\title{
O DRAMA CAMPONÊS NO CERRADO SUL MARANHENSE: conflitos socioterritoriais no campo em Balsas - MA
}

\author{
THE PEASANT DRAMA IN SOUTHERN MARANHENSE \\ CERRADO: socio-territorial conflicts in the Balsas countryside
}

\author{
Vanderson Viana Rodrigues \\ Universidade Estadual do Maranhão, Departamento de História e Geografia, São Luís, MA, Brasil \\ vanderson2016rodrigues@gmail.com \\ Ademir Terra \\ Universidade Estadual do Maranhão, Departamento de História e Geografia, São Luís, MA, Brasil \\ ademirterra@professor.uema.br
}

\begin{abstract}
Resumo
Os conflitos agrários entre camponeses e produtores de commodities no município de Balsas, no Maranhão, têm sua gênese na década de 1970, ligada às políticas de povoamento e incentivos agrícolas efetivadas pelos governos militares. A chegada de novos moradores ao município mudou o modo de vida da população local, pois trouxeram consigo culturas, hábitos e tradições oriundos da sua terra natal, no sul do país. Todavia, o cultivo mecanizado em áreas de cerrado, com topografia plana, e com rápida correção mineral, foi o elemento novo mais significativo trazido por esses migrantes, com repercussões tanto no meio rural, quanto no urbano. A territorialização desse novo ator social fez emergir novos e contundentes conflitos socioterritoriais que seguem até os dias atuais e se tornam cada vez mais complexos, ou seja, a nova atividade desenvolvida no campo, além de não incluir os camponeses, provoca mudanças quantitativas e qualitativas significativas no meio ambiente e na sociedade. A presente pesquisa, objetiva trazer à luz tais conflitos, rompendo assim com uma espécie de "pacto de silêncio" entre as autoridades e a maioria dos veículos de imprensa do município que marginaliza os camponeses e ignora suas lutas, por não estarem vinculados aos interesses da classe hegemônica local.
\end{abstract}

Palavras-Chave: Conflitos. Camponeses. Sojicultores. Balsas - MA.

\begin{abstract}
The agrarian conflicts between peasants and commodity producers in Balsas municipality, Maranhão, have their genesis in the 1970s, linked to settlement policies and agricultural incentives implemented by the military governments. The arrival of new residents to the municipality changed the local population way of life because they brought with them cultures, habits, and traditions from their native land in the south of the country. However, mechanized cultivation in Cerrado areas with flat topography and a fast mineral correction were the most significant new elements brought by these migrants, with repercussions both in rural and urban environments. The territorialization of the new social actors gave rise to new and strong socio-territorial conflicts that continue
\end{abstract}


until now and become increasingly complex. In other words, the new activity developed in the field, besides not including the peasants, causes significant quantitative and qualitative changes in the environment and in society. This research aims to bring to light such conflicts, thus breaking with a kind of "silence pact" between the authorities and most of the municipality's media outlets that marginalize peasants and ignore their struggles, because they are not linked to the interests of the local hegemonic class.

Keywords: Conflicts. Peasants. Soybean farmers. Balsas-MA.

\section{Introdução}

O presente texto resulta das análises desenvolvidas no âmbito do projeto Impactos Socioambientais da Agricultura Científica Globalizada na Microrregião Gerais de Balsas no Maranhão - realizado no biênio 2017-2018 pelo Grupo de Estudos e Pesquisas sobre a Questão Agrária e Movimentos Sociais - GEPQAM, que integra o Centro de Educação, Ciências Exatas e Naturais - CECEN da Universidade Estadual do Maranhão - UEMA. Objetiva trazer à luz os conflitos socioterritoriais que insurgem, envolvendo camponeses e sojicultores, em razão da territorialização e espacialização da agricultura científica globalizada no município de Balsas, no Maranhão (Mapa 1), rompendo assim com uma espécie de "pacto de silêncio" existente entre as autoridades e a maioria dos veículos de imprensa do município que mantém vínculo com o agronegócio e, por isso mesmo, marginaliza os camponeses e ignora suas lutas, por não estarem ligados aos interesses da classe hegemônica local.

Para alcançar tal objetivo, foi necessário empreender reflexões teóricas visando caracterizar território, conflitos e campesinato, traçar um perfil dos principais conflitos socioterritoriais, bem como confrontar as distintas percepções acerca deles. Tendo por base periódicos, livros e outras fontes - como os censos econômicos e demográficos do Instituto Brasileiro de Geografia e Estatística - IBGE e também o banco de dados sobre os conflitos no campo da Comissão Pastoral da Terra - CPT -, realizamos o procedimento apontado por Pisciotta (2003) como uma "pesquisa de caráter bibliográfico em busca de dados secundários" sobre temáticas como: território, territorialidades, disputas por terra, produção e espacialização da soja, conflitos agrários, agronegócio e produção camponesa, com o intuito de aprofundar a análise desses conceitos.

Visando à obtenção de dados primários, desenvolvemos atividades de campo no município de Balsas, no período de 28 de janeiro a 15 de fevereiro de 2018, quando foram 
realizadas uma roda de conversa e entrevistas com sete camponeses do Assentamento Rural Gado Bravinho; duas rodas de conversas e entrevistas com dez camponeses do Assentamento Rural São José. Paralelamente, entrevistamos oito sojicultores e empreendemos visitas às entidades e organizações que representam os dois grupos de agentes sociais do campo no município, os camponeses e os grandes produtores rurais.

Mapa 1 - Localização Geográfica do Município de Balsas no Maranhão

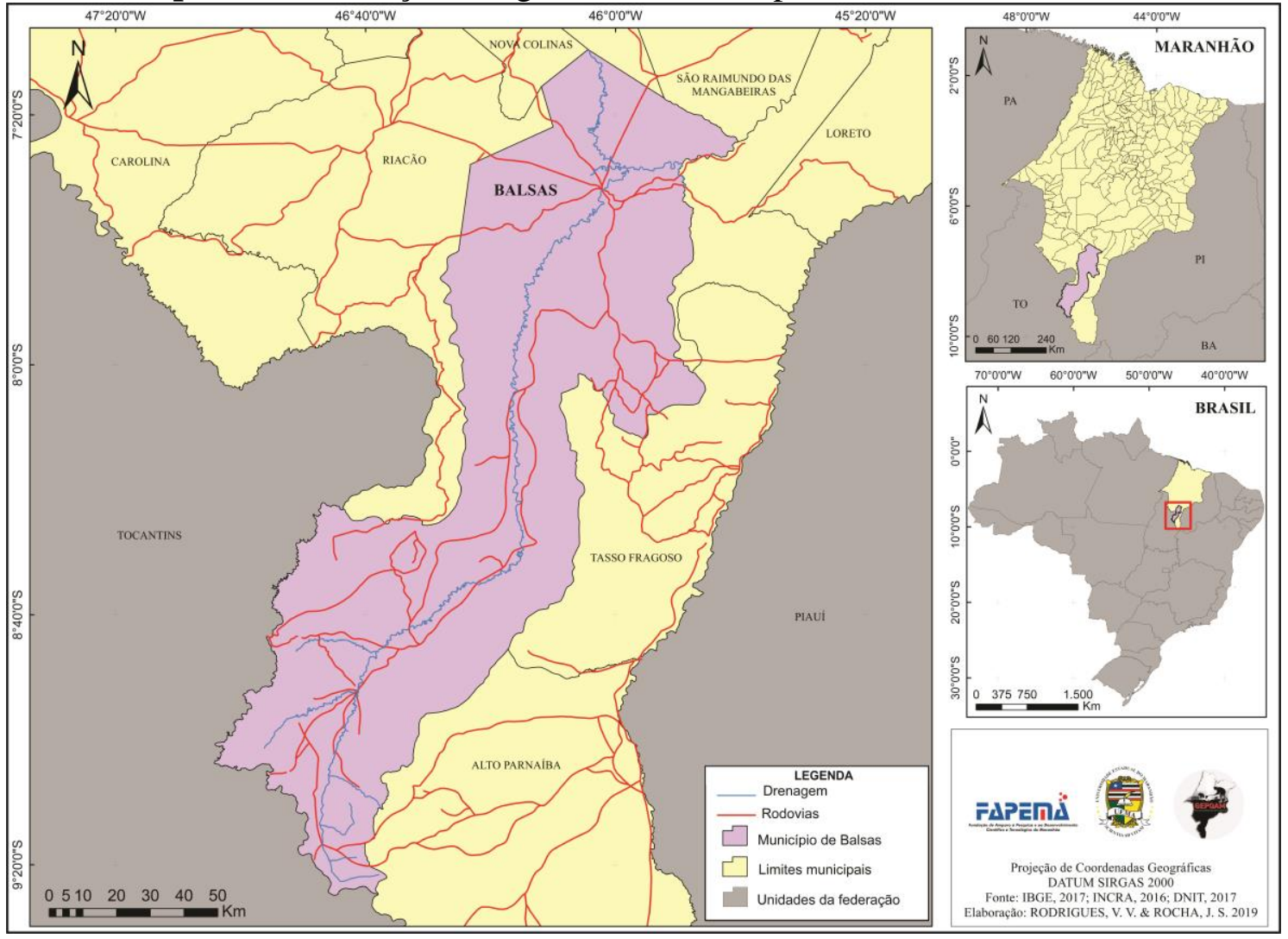

Fonte: INCRA.

Amparados nesses instrumentos de pesquisa, obtivemos dados qualitativos e quantitativos que, examinados sob o aporte do método do materialismo histórico - o qual possibilita analisar como o homem se organiza, através dos tempos, na produção e reprodução do capital - nos permitiram montar um histórico dos conflitos socioterritoriais que envolvem esses distintos agentes sociais, bem como nos proporcionaram uma melhor compreensão da complexidade de relações existente no campo no município maranhense de Balsas, que vai muito além da retórica desenvolvimentista de que se valem os arautos do agronegócio. 
A partir dos dados levantados, procedemos à análise dos conflitos pela posse da terra oriundos do processo de mudanças ocorrido no município, provocado pela territorialização e espacialização da lavoura, dando ênfase aos grupos sociais marginalizados (LITTLE, 2006) - os mais afetados pelas relações assimétricas de poder (ZHOURI e OLIVEIRA, 2007) - e analisando as especulações de legitimação das práticas sociais na apropriação do espaço e de seus recursos naturais.

Os conflitos agrários entre camponeses e produtores de commodities no município de Balsas, no Estado do Maranhão, têm sua gênese na década de 1970, ligada às políticas de povoamento e incentivos agrícolas implantadas pelos governos militares. Até então, a região era ocupada por camponeses, os quais criavam animais de pequeno porte e cultivavam lavouras de subsistência, em sua grande maioria, em terras devolutas ou em fundos de pastos de pequenos donos de terra. $\mathrm{O}$ excedente dos produtos cultivados era vendido a atravessadores às margens do Rio Balsas ${ }^{1}$, de onde seguia para ser comercializado em outros municípios do sul do estado.

Compreendemos o camponês como um agente social do campo, cuja economia, segundo Carvalho (2014) baseado em premissas de Chayanov (1925), se caracteriza por estar centrada na mão de obra familiar e sem influência externa: “[...] a família e as relações que dela ressaltam têm que ser o único elemento organizador da economia sem assalariados" (CARVALHO, 2014, p. 195). Sendo poliprodutor, cultiva quase tudo aquilo que precisa para sua alimentação e, como destacam Carvalho e Costa (2012), detém algumas peculiaridades únicas:

- Os saberes e as experiências de produção vivenciados pelas famílias camponesas são referenciais importantes para a reprodução de novos ciclos produtivos;

- As práticas tradicionais, o intercâmbio de informações entre vizinhos, parentes e compadres, o senso comum, assim como a incorporação gradativa e crítica de informações sobre as inovações tecnológicas que se apresentam nos mercados, constituem um amálgama que contribui para as decisões familiares sobre o que fazer;

- O uso da terra pode ocorrer de maneira direta pela família, em parceria com outras famílias vizinhas ou parentes, em coletivos mais amplos ou com partes do lote arrendados a terceiros;

- Há diversificação de cultivos e criações, alternatividade de utilização dos produtos obtidos, seja para o uso direto da família, seja para usufruir de oportunidades nos mercados, e presença de diversas combinações entre produção, coleta e extrativismo;

- A unidade de produção camponesa pode produzir artesanalmente e fazer o beneficiamento primário de produtos e subprodutos; 
- Existe garantia de fontes diversas de rendimentos monetários para a família, desde a venda da produção até a de remuneração para dias de serviço de membros da família;

- A solidariedade comunitária (troca de dias de serviço, festividades, celebrações), as crenças e os valores religiosos por vezes empregados às práticas da produção;

- Estão presentes elementos da cultura patronal;

E, fim, mas não finalmente, existem relações afetivas e simbólicas com as plantas, os animais, as águas, os sítios de infância, com a paisagem... e com o tempo. (CARVALHO; COSTA, 2012, p. 27).

Esse modo de vida, até então predominante em Balsas, no sul do Maranhão, passou a sofrer as consequências da chegada de novos moradores ao município, que trouxeram consigo culturas, hábitos e tradições provenientes da sua terra natal, no sul do país. Todavia, o elemento novo mais significativo trazido por esses migrantes foi instalado no campo, com repercussões tanto no meio rural, quanto no urbano: o cultivo de lavouras mecanizadas em áreas de cerrado, com topografia plana, em que a necessidade de correção mineral para uma melhor produtividade não foi empecilho para a territorialização e a espacialização da agricultura técnico-cientifica na região, especialmente, da sojicultura.

A territorialização desse novo agente social, oriundo de uma realidade diversa, fez emergir novos e contundentes conflitos socioterritoriais que permanecem até os dias atuais e que se requalificam e se tornam cada vez mais complexos, posto que as atividades por ele desenvolvidas nem sempre têm sido executadas sob os melhores critérios do ponto de vista de preservação da natureza e da valorização da territorialidade preexistente. Dessa forma, têm início as animosidades, desde que, se para os produtores de commodities, sob a perspectiva capitalista, o território tem caráter de propriedade, mercadológico, em que "quanto mais se produz, mais valor agregado a ele existirá" (FERNANDES, 2012, p. 744), para os camponeses, o território “[...] é uma unidade de produção familiar e local de resistência da família, que muitas vezes pode ser constituída de mais de uma família" (FERNANDES, 2012, p. 744).

Fernandes (2015) propõe uma tipologia de território, categorizando-o em diversas escalas a partir de complexidades, usos, desusos, conflitos e contradições:

[...] o primeiro território é o espaço de governança da nação. É o ponto de partida da existência das pessoas [...]. O segundo refere-se à propriedade como espaço de vida, que pode ser particular ou comunitária [...]. E o terceiro é o território relacional, visto sob a perspectiva de suas conflitualidades [...]." (FERNANDES, 2015, p. 208). 
Entendemos como território do agronegócio aquele que capitaliza o campo e tem como medida o valor do produzido. Nele se encontram as articulações capitalistas, as relações comerciais e de lucro, cuja relevância é dada pelo mercado internacional e suas demandas, enfim, um território dos relacionamentos extraterritoriais, considerado um substrato dos alinhavos do lucro e dos interesses de fluxos.

Segundo Haesbaert (2007), "o território, de qualquer forma, define-se antes de tudo com referência às relações sociais (ou culturais, em sentido amplo) em que está mergulhado, relações estas que são sempre, também, relações de poder”. Para este autor, o território, em qualquer acepção, relaciona-se ao poder, “[...] mas não apenas ao tradicional 'poder político'. Ele diz respeito tanto ao poder no sentido mais explícito, de dominação, quanto ao poder no sentido mais implícito ou simbólico, de apropriação" (HAESBAERT, 2004, p. 2).

Para o camponês, o território é carregado de identidade, características e complexidades, pois ele tem na unidade de produção familiar a centralidade do seu trabalho e mão de obra, sempre ligado a terra/território seja por afeto ou cultivo, e não busca acúmulo de capital. Diferenciando-se, assim, de um microempresário familiar, microprodutor familiar, ou agricultor familiar, ele busca seu sustento e independência econômica e alimentar.

É, portanto, sob esse prisma, que serão analisados aqui os conflitos socioterritoriais que insurgem no município maranhense de Balsas, envolvendo camponeses e produtores de commodities, em razão da territorialização e espacialização da agricultura científica globalizada, suas relações e arranjos conflitantes que se materializam na complexidade do território ou na sobreposição de territórios (do camponês e do agronegócio).

\section{Conflitos socioterritoriais no campo}

Os conflitos aqui analisados são entendidos como parte da dinâmica socialmente construída, assim como o território, pois eles advêm das relações de classe e de poder emergentes nos territórios estudados, fruto das diferentes territorializações e sobreposições sociais, econômicas e de interesses. Partimos da concepção de que conflitos constituem 
Um desentendimento entre duas ou mais pessoas sobre um tema de interesse comum, representam a dificuldade de lidar com as diferenças nas relações e diálogos, associada a um sentimento de impossibilidade de coexistência de interesses, necessidades e pontos de vista. (TERRA, 2016, p. 177).

Dois pontos dessa assertiva são fundamentais para a presente análise: 1) o "tema de interesse comum”, que remete ao domínio do território, inicialmente, sob o controle dos camponeses e, agora, pertencente ao agronegócio ou por ele almejado; 2) "a dificuldade de lidar com as diferenças nas relações e diálogos", visto não ser possível esperar relações cordiais quando elas são assimétricas, tampouco um diálogo entre atores sociais com interesses divergentes, em que a dialética não prevalece.

Isso é o que ocorre quando o agronegócio, ator econômico e político hegemônico que quase sempre nega a existência do camponês, num exercício de exclusão, impõe suas regras e suprime a diferença, por não suportá-la, moldando-a de acordo com suas próprias conveniências e destituindo o camponês de toda sua positividade, ao ponto de sua completa obliteração. Conflitos socioterritoriais, portanto, são aqueles que envolvem grupos sociais distintos e com interesses adversos, em razão da disputa por territórios sobrepostos.

\section{Conflitos socioterritoriais no campo em Balsas, no Maranhão}

Os conflitos agrários que permeiam o território camponês e do agronegócio, vistos pelas duas linhas opostas e dialogando com nosso método, são entendidos como “[...] ações de resistência e enfrentamento que acontecem em diferentes contextos sociais no âmbito rural, envolvendo a luta pela terra, água, direitos e pelos meios de trabalho ou produção" (CPT, 2007, p. 10). Eles se caracterizam de muitas maneiras: embora primeiramente ocorra o conflito espacial pela produção, que se dá de modo encoberto/camuflado, como veremos mais adiante, sua forma violenta é a mais cruel, pois desaloja, deixa sequelas e mata.

As políticas brasileiras atuais para a reforma agrária ${ }^{2}$ não abrangem as especificidades das disputas por terra no Maranhão, assim como no restante do país. No atual contexto, os camponeses são pressionados pela territorialização e espacialização das lavouras técnico-científicas, o que tem colocado em xeque o seu modo de uso da terra e de vida. São esmagados pelo avanço do cultivo de commodities que, pela exacerbada 
utilização de agrotóxicos, contamina as águas, o solo e mata a fauna, bem como promove a desenfreada devastação do bioma do cerrado.

A implantação do cultivo de soja no município de Balsas, no sul do Maranhão, e, posteriormente, no leste do estado, trouxe consigo novas práticas agrícolas que provocaram grandes mudanças. A "roça" tradicional passou a ter como vizinho as grandes lavouras de grãos, as quais foram/estão sendo instaladas, preferencialmente, no topo das chapadas, altas e planas, ideais para a implantação da lavoura mecanizada. A necessidade de correção mineral do solo, para alcançar maior produtividade, não foi empecilho para a territorialização e a espacialização da agricultura técnico-científica globalizada, que acabaram por fazer emergir conflitos relacionados à disseminação de novas territorialidades (Fotografia 1).

Fotografia 1 - Produção de soja com emprego de irrigação nas chapadas de Balsas - MA

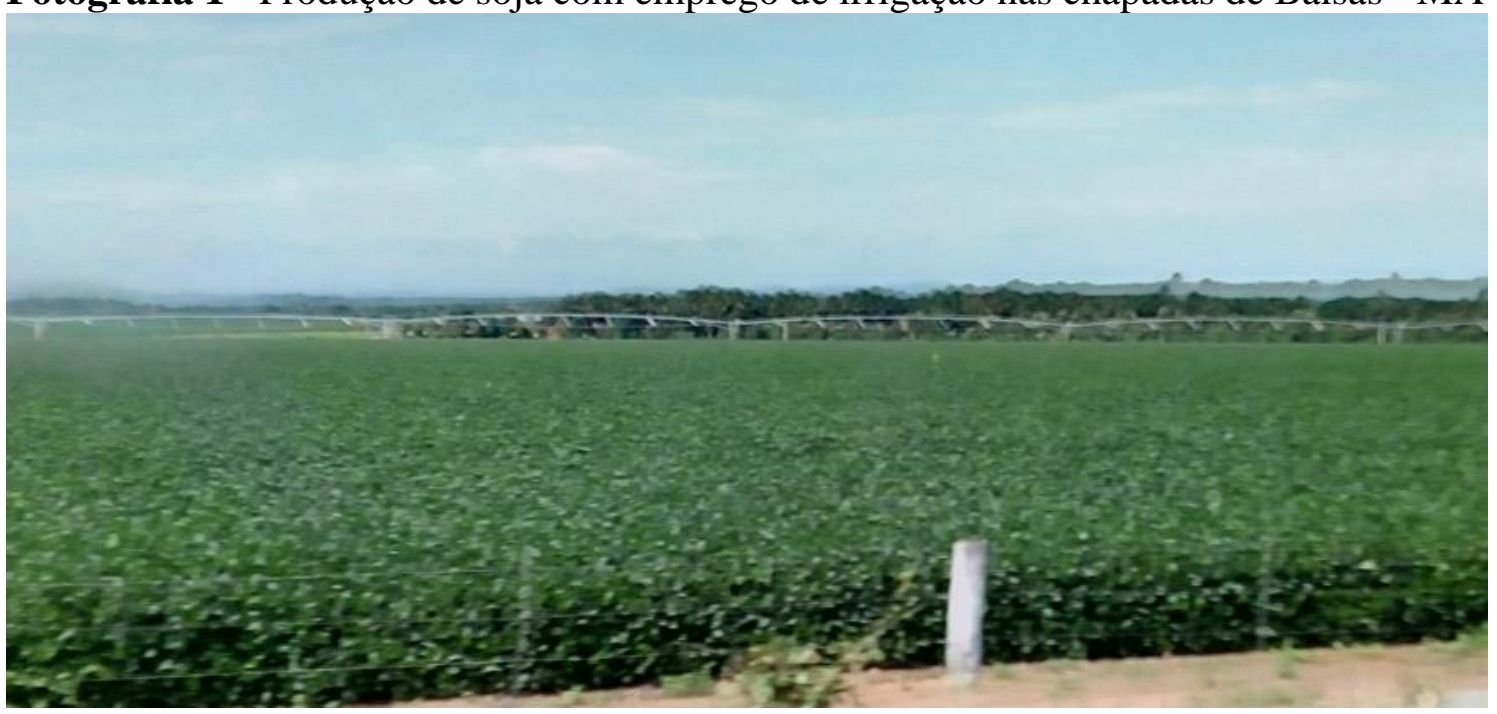

Fonte: Pesquisa de campo, 2018.

A imposição de determinadas culturas agrícolas, neste caso, a produção de grãos, é uma das categorias de conflitos existentes entre o agronegócio e o campesinato na região em análise. Tais conflitos não são percebidos pela totalidade da sociedade balsense, visto que as autoridades locais e os veículos de comunicação, cujos interesses estão atrelados ao agronegócio, em geral, se encarregam de não dar visibilidade a esse tipo de problema. Consequentemente, como sua apreensão só pode ocorrer a partir da análise de dados, esse pacto de silêncio por parte dos gestores locais e da imprensa marginaliza os camponeses, por não estarem vinculados aos interesses econômicos desses segmentos. 
Contudo, os camponeses impõem resistência ao avanço do agronegócio sobre seu(s) território(s), e essa resistência constitui uma forma de manutenção dos seus próprios meios de produção e do seu peculiar modo de vida, ou seja, buscam, através dela, o protagonismo da sua própria história e a não submissão aos ditames do capital, que se vale de todos os meios para esmagar a territorialidade e a cultura camponesa, ao subtrairlhes o território, ou tão somente a renda da terra.

O território é, para o camponês, mais que o substrato para a sua produção, é carregado de afeto, apego, religiosidade e rugosidade (SANTOS, 1977) e, mesmo que nele trabalhe penosamente com sua família, ele também é mais amplo que qualquer ponto de vista, seja qual for o analista. $\mathrm{O}$ território camponês é fruto de muita resistência às múltiplas investidas e formas de ação do capitalismo.

Como reação a esse processo, ocorre a luta pela terra a as ocupações, na tentativa de criação e recriação da condição camponesa: campesinato e território são indissociáveis, e a separação entre eles pode significar a destruição de ambos. (FERNANDES, 2012, p. 175).

Além do apego afetivo ao território, o camponês também o tem como substrato para o exercício das atividades necessárias à manutenção e reprodução da sua família, ou seja, da sua condição mesmo de camponês, como poliprodutor e pluriativo na sua essência. Tais características foram constatadas quando da realização dos trabalhos de campo da presente pesquisa.

\section{Balanço dos conflitos socioterritoriais no campo no município de Balsas, no Maranhão}

No município de Balsas, considerando o período de 2001 a 2017, a ocorrência de conflitos por terra apresentou acirramento, em especial nos anos de 2008 e 2010 (Gráfico 1), quando ocorreram sete casos de disputa de terras entre camponeses e produtores do agronegócio. Esse levantamento, realizado pela Comissão Pastoral da Terra - CPT ao longo dos anos, engloba os conflitos com maior visibilidade, aqueles que os camponeses denunciam ou comunicam aos próprios agentes da CPT. Nos últimos cinco anos, porém, os enfrentamentos tiveram uma significativa queda - em média 0,6 disputa por ano no município -, o que pode ser computado à extensão da espacialização das lavouras técnicocientíficas para municípios vizinhos a Balsas. 
No ano de 2017, quando a situação parecia estabilizada, ocorreu um pequeno aumento nos conflitos. Segundo os agentes policiais do município de Balsas, essas ocorrências ainda estão em fase de investigação, mas tiveram como lócus os Projetos de Assentamento (PA) São José e Gado Bravinho. Esses conflitos foram provocados por "demandas" dos produtores de lavouras mecanizadas que buscavam se apropriar de áreas ainda cobertas por vegetação de cerrado, para transformá-las em suas Áreas de Preservação Permanente (APP), mesmo porque não são adequadas para o cultivo mecanizado, tendo, assim, à sua disposição, toda a parte localizada nas chapadas, ideal para o desenvolvimento de suas lavouras. Esses conflitos ocorrem pela pressão dos fazendeiros sobre as áreas de assentamentos rurais e/ou ocupadas por populações camponesas nas vizinhanças.

Gráfico 1 - Número de Conflitos Agrários e da Criação de Assentamentos Rurais em Balsas - MA entre 2001 e 2017

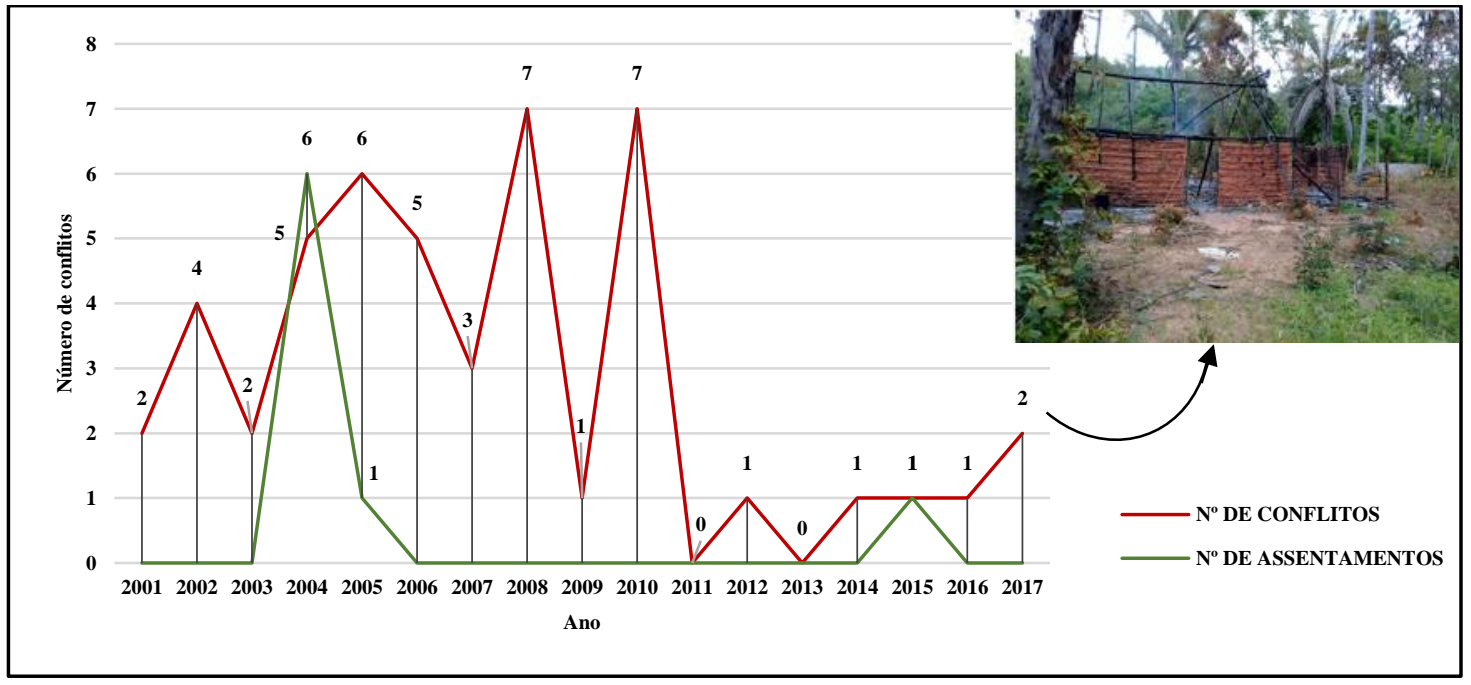

Fonte: CPT, INCRA, 2017.

Observa-se que em alguns desses lugares já existem assentamentos rurais, ou estão em fase de implantação. São geridos pelo Instituto Nacional de Colonização e Reforma Agrária (INCRA), pelo Núcleo Estadual de Programas Especiais (NEPE), ou pelo Instituto de Colonização e Reforma Agrária do Maranhão (ITERMA), órgãos que, todavia, pouco têm intervindo na questão, a fim de impedir a ocorrência de confrontos.

Além disso, implantam assentamentos em áreas "ilhadas por um mar de soja", cuja localização é responsável pela insurgência de inúmeros conflitos que afetam diretamente a territorialidade dos assentados. Um deles é a interferência no sistema de 
produção praticado pelas famílias camponesas, no que concerne à criação dos animais: o costume é cercar as roças, para que os animais pastoreiem nas áreas de uso comum (a chapada). Na situação atual, ocorre o inverso, pois como os campos de soja não são cercados, a criação de animais é que deve ser restringida.

Para ilustrar tais conflitos, e a título de exemplo, passamos a discorrer, a seguir, sobre os assentamentos rurais São José e Gado Bravinho, ambos localizados no município de Balsas, no Maranhão, e que vivem as agruras decorrentes de sua localização geográfica, rodeados por fazendas do agronegócio.

\section{Assentamentos Rurais São José e Gado Bravinho: a incômoda vizinhança}

A reforma agrária é um processo permeado de contradições e conflitos entre atores que possuem interesses divergentes. Dessa forma, os assentamentos rurais constituem "espaços de relações sociais, onde as características heterogêneas individuais, homogeneizadas no processo de luta pela terra, ressurgem em novas bases" (ZIMMERMANN, 1994, p. 205), revelando, de acordo com Terra (2011, p. 8), “o desejo de autonomia dos sujeitos e gerando embates que se expressam no cotidiano, como parte de um complexo jogo de forças geopolíticas”.

Neles, são abrigadas famílias que, em sua maioria, há anos lutam para obter sua terra ou nela se manter, numa peleja digna, que busca apenas a legitimidade dos direitos assegurados pela Lei $n^{\circ} 4.504 / 64$, cujo artigo $2^{\circ}$ e seu $§ 1^{\circ}$ trazem a seguinte redação:

\footnotetext{
É assegurada a todos a oportunidade de acesso à propriedade da terra, condicionada pela sua função social, na forma prevista na lei.

$\S 1^{\circ}$ A propriedade da terra desempenha integralmente a sua função social quando, simultaneamente:

a. favorece o bem-estar dos proprietários e dos trabalhadores que nela labutam, assim como de suas famílias;

b. mantém níveis satisfatórios de produtividade;

c. assegura a conservação dos recursos naturais;

d. observa as obrigações legais que regulam as justas relações de trabalho entre os que a possuem e a cultivam. (BRASIL, 1964)
}

Os assentamentos, regulamentados pelo INCRA, são criados a partir de decretos assinados pela presidência da república. Segundo Leite (2012), estão atrelados, por um lado, à atual ação estatal direcionada ao controle e à delimitação do novo "espaço" criado e, por outro, às características dos processos de luta e conquista da terra empreendidos pelos trabalhadores rurais. 
De acordo com Martins (2000, p. 46), os projetos de assentamentos são "uma verdadeira reinvenção da sociedade", caracterizando-se como "uma clara reação aos efeitos perversos do desenvolvimento excludente e da própria modernidade". Para Terra (2011, p. 12), a partir do momento em que as famílias se apossam "formalmente dessa terra, construindo sua nova identidade social, estará estabelecido um processo inteiramente novo, uma vez que nesse espaço imprimir-se-á uma nova organização, um microcosmo social".

Para uma melhor compreensão dos conflitos no município de Balsas, foram escolhidos dois assentamentos do INCRA que se encontram em fases diferentes de instalação e nos quais as causas dos confrontos são diversas também.

Primeiramente, visitamos o Assentamento São José, localizado a 90 km da sede do município de Balsas, implantado há 12 anos, onde, ao longo desse tempo, foram registrados diversos conflitos territoriais, por várias razões, mas principalmente em função da topografia do lugar, que apresenta características almejadas pelos produtores de grãos da região. Posteriormente, a visita foi ao Assentamento Gado Bravinho, localizado a aproximadamente $70 \mathrm{~km}$ do sítio urbano de Balsas, e que ainda está em fase inicial de implantação, tendo sido criado há pouco mais de dois anos. Enfrenta, atualmente, diversas dificuldades estruturais e de afirmação como território camponês, transformado em palco de diversos conflitos territoriais entre os assentados e os representantes do agronegócio.

Em entrevista, o atual presidente da associação do Assentamento São José (Fotografia 3), afirmou haver agora uma pausa nos conflitos, ainda que a área esteja cercada por fazendas produtoras de soja. Contudo, as famílias ali instaladas sofrem as consequências por estarem "ilhadas por um mar de soja", entre elas, e mais grave, a constante exposição dos assentados aos agrotóxicos aplicados nas grandes plantações de soja, que são transportados por suspensão, ocasionando diversos malefícios aos camponeses: há relatos de surtos alérgicos que teriam sofrido e, também, sobre a contaminação do Riacho São José, - do qual as famílias coletam água para o consumo diário - decorrente do recebimento de produtos químicos utilizados nas lavouras.

A referida liderança relata ainda o assédio praticado por alguns fazendeiros, tentando persuadir os assentados a vender seus lotes. A título de exemplo, narrou um episódio acorrido em 2016, quando um deles, decidido a vender seu lote para um 
fazendeiro vizinho ao Assentamento, só não concretizou o negócio porque, além de se tratar de transação ilegal, a própria comunidade se mobilizou para impedi-lo.

Cabe observar que, do ponto de vista do presidente da associação do Assentamento São José, nem o problema da contaminação do riacho, fonte de abastecimento das famílias e base para todas as suas atividades econômicas, nem o assédio dos membros da comunidade com vistas a fragilizar os assentados e, consequentemente, colocar em risco a própria existência do Assentamento, configuram um conflito, ou causa imediata para desencadeá-lo. Seu posicionamento possivelmente decorra, entre outras causas, do conformismo, da ignorância, do medo do confronto, ou da condição de subordinação a que historicamente o campesinato está submetido. $\mathrm{O}$ fato é que o agronegócio, como atividade econômica hegemônica, e os seus representantes políticos despoticamente dominantes se aproveitam sem qualquer pudor dessa condição de alienação dos camponeses, principalmente daqueles não vinculados a movimentos sociais de luta pela/na terra.

Fotografia 3 - Agrovila do Assentamento Rural São José em Balsas - MA

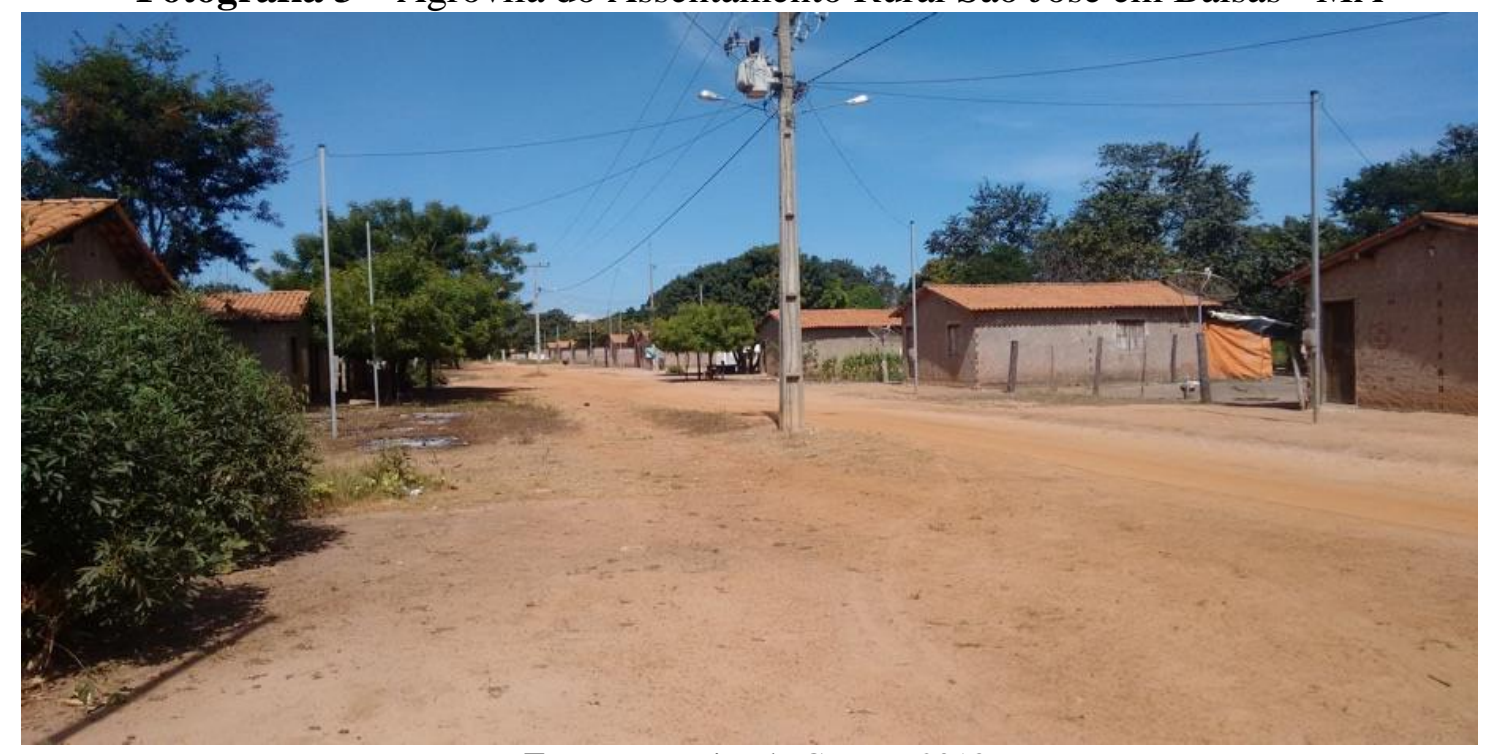

Fonte: Pesquisa de Campo, 2018.

Já no Assentamento Gado Bravinho (Fotografia 4), outra base empírica da pesquisa, os conflitos ocorrem em razão do lento processo de implantação. Ainda que toda a documentação esteja homologada e deferida, o Assentamento na prática ainda não foi instalado, ou seja, existe de direito, mas não de fato. Tal circunstância tem causado situações conflituosas entre aqueles que são oficialmente os destinatários da área e os 
grileiros, que, na maioria das vezes, são representantes do agronegócio na região, alguns, proprietários de áreas limítrofes do Assentamento e com pretensões de ampliar seus domínios. A impressão que se tem é que o INCRA tem sido pouco sensível aos problemas que afligem os camponeses e omisso na resolução da contenda que envolve a grilagem das terras destinadas aos assentados.

Em visita ao Assentamento realizada em 08 de fevereiro de 2018, constatamos a falta de demarcação definitiva dos lotes de cada assentado e a completa ausência de obras, seja a construção da agrovila, seja qualquer outra benfeitoria necessária para sua definitiva instalação. No local, encontram-se apenas barracos onde os camponeses improvisaram suas habitações, bem como um deles que serve de escola, em condições muito precárias, defendida com muito vigor, porém, pelos camponeses, expressão da importância conferida à educação dos filhos. O presidente da associação dos assentados relatou que seus pais teriam chegado a essas terras em 1987, antes mesmo de todos aqueles que hoje afirmam serem os proprietários da área, segundo ele, cinco grileiros nela instalados. Ali, onde os enfrentamentos são constantes, é comum ocorrer, entre outras formas de pressão, ameaças explícitas e/ou veladas, corte de arames das cercas, incêndios de casas ou plantações e disparos a esmo de armas de fogo, no intuito de aterrorizar os camponeses.

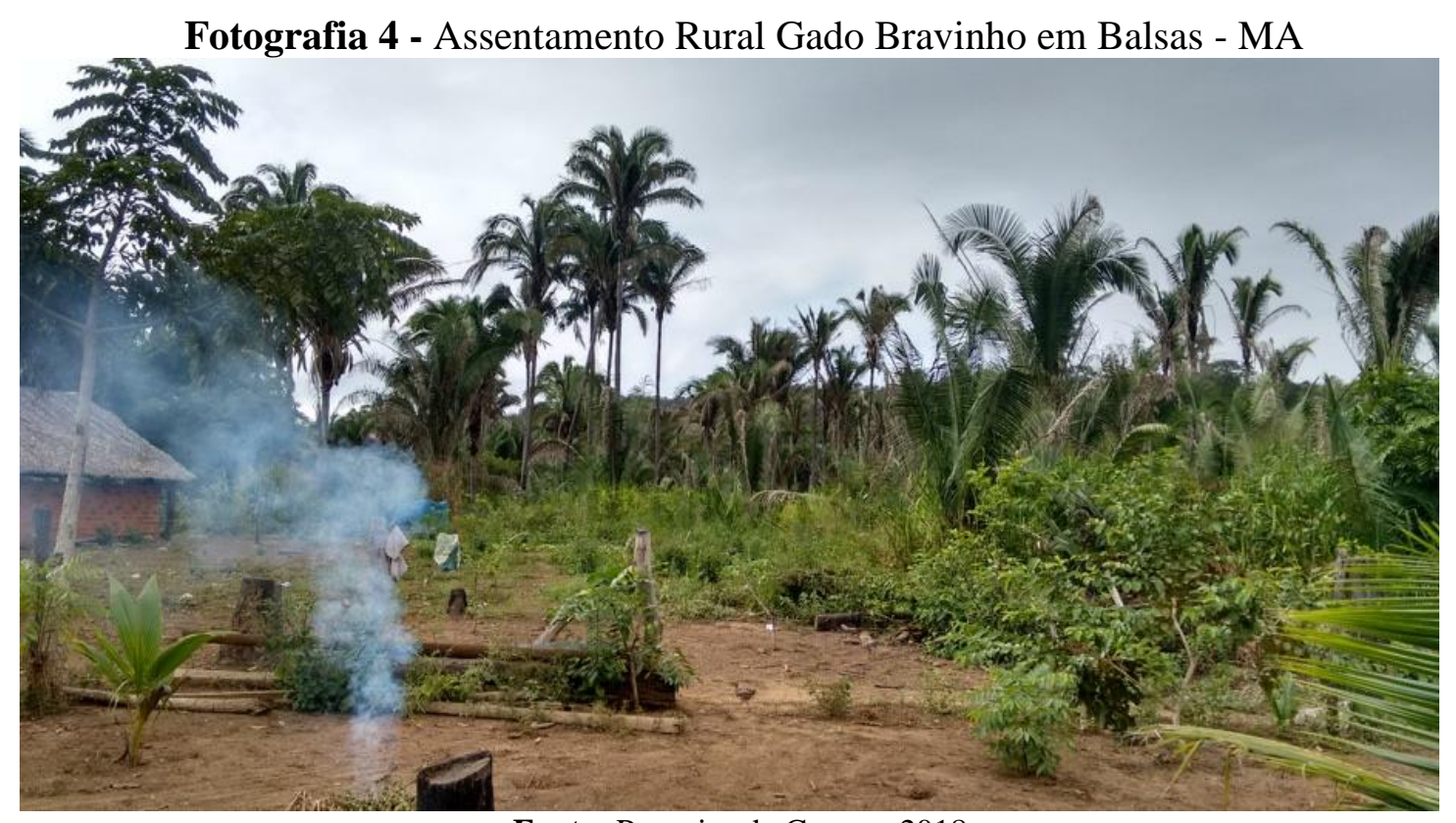

Fonte: Pesquisa de Campo, 2018. 
Uma peculiaridade desse Assentamento é a organização espacial da área pelos camponeses, que preferem instalar suas moradias e suas roças na parte baixa do terreno, mais adequada à forma de exploração camponesa. Além de não competirem espacialmente com a soja devido à sua topografia, muitas vezes mais íngreme e não favorável à mecanização, essas áreas são mais úmidas e possuem maior disponibilidade de nutrientes mais aflorados. Ainda assim, representam obstáculos aos camponeses, pois o acesso é mais difícil, obrigando-os a circular por estradas muito precárias. O maior problema, no entanto, reside no fato de ser esse terreno alvo da cobiça dos latifundiários, que desejam utilizá-lo para a composição de reservas legais, deixando todo o espaço das chapadas disponível para a grande lavoura mecanizada.

\section{Considerações Finais}

É perceptível que os conflitos socioterritoriais entre camponeses e representantes do agronegócio no município de Balsas, no Maranhão, ocorrem em função do avanço da lavoura capitalista na região e tiveram seu ápice no ano de 2010, quando sete enfrentamentos se sucederam, envolvendo cerca de 902 famílias, em uma área de 10.158 ha.

Hoje, os conflitos continuam a acontecer, de forma explícita ou velada, pois o grande capital forma um monopólio a seu favor, desapropriando, desvalorizando e desarticulando as comunidades campesinas, as quais, parcialmente organizadas, com o auxílio de algumas entidades que atuam em favor de seus interesses, como o Sindicato de Trabalhadores Rurais, a Associação Camponesa e a Comissão Pastoral da Terra, lutam, no limite das condições sociais impostas pelo poder hegemônico regional, pela manutenção do território e do modo de vida campesino, bem como pela conquista de novas áreas.

\section{Notas}

\footnotetext{
1 O Rio Balsas, principal afluente do Rio Parnaíba, é o maior curso d'água do município de Balsas e o corta de norte a sul, com navegabilidade para pequenas embarcações (Balsas). Já foi uma importante via de escoamento da produção dos camponeses e de frutos coletados por eles no cerrado maranhense. Hoje, tem sido utilizado em grande parte para lazer e turismo, além de ter suas águas extraviadas para a irrigação de lavouras de grãos e a criação de peixes.
} 
2 Tendo em vista a atual conjuntura do programa de reforma agrária brasileiro, entendemos que ele não promove a dita "reforma", mas representa uma política de amenizar conflitos ou propor assentamentos, a qual visa somente a apagar a emergência de conflitos e disputas, concedendo terras que alimentam a reforma agrária de mercado a camponeses que são desterritorializados pelos interesses capitalistas de certos grupos sociais privilegiados.

\section{REFERÊNCIAS}

BRASIL. Lei $\mathbf{n}^{\circ}$ 4.504, de 30 de novembro de 1964. Disponível em:

<http://www.planalto.gov.br/ccivil_03/leis/L4504.htm>. Acesso em: 20 abr. de 2019.

CARVALHO, H. M. (Org.) Chayanov e o Campesinato. São Paulo: Expressão Popular, 2014.

CARVAlHO, H. M. COSTA, F. A. Agricultura Camponesa. In; CALDART, R. S. et al. (Org.) Dicionário da Educação do campo. Rio de Janeiro e São Paulo: Escola Politécnica de saúde Joaquim Venâncio, Expreção Popular, 2012. p. 32 - 40.

CHAYANOV, A. V. La organización de la unidad económica campesina. Buenos Aires: Nueva Visión, (1925). 1974.

Comissão Pastoral da Terra - CPT. Áreas em Conflito - Serie: 2015 a 2006. Disponível em: <https://www.cptnacional.org.br/index.php/component/jdownloads/category/4areas-emconflito?Itemid=-1>. Acesso em: 20 de abr. 2019.

Ocorrência de Conflito por Terra. Serie: 2015 a 2010. Disponível.em: <https://www.cptnacional.org.br/index.php/component/jdownloads/category/36conflitos -por-terra-ocorrencias?Itemid=-1> Acesso em: 20 de abr. 2019.

FERNANDES, B. M. Sobre a tipologia de territórios. In. SAQUET, M. A. \& SPOSITO, E. S. Territórios e territorialidades: teorias, processos e conflitos. Rio de Janeiro: Editora Consequência, 2015, p. 208.

. Território Camponês. In. CALDART, R. S. et al. Dicionário da educação do campo. São Paulo: Expressão Popular, 2012, p. 744.

Teoria dos territórios e da questão agrária. São Paulo: Edunesp, 2008. p. 296.

HAESBAERT, R. Dos múltiplos territórios a multiterritorialidade. In: HEIDRICH, A.; COSTA, B.; PIRES, C.; UEDA, V. (Org). A emergência da multiterritorialidade: a ressignifcação da relação do humano com o espaço. Canoas/Porto Alegre: Editora ULBRA/Editora UFRGS, 2004. Disponível em: <http://www.ufrgs.br/petgea/Artigo/rh.pdf>. Acesso em: 20 abr. 2019.

HAESBAERT, R. Concepções de território para entender a desterritorialização. In; SANTOS, M. et al. (Org.) Território, territórios: ensaios sobre o ordenamento territorial. Rio de Janeiro: Lamparina, 3. Ed. p. 54. 2007. 
LEITE, A. E. Os Conflitos Socioambientais: Um Campo de Estudo e de Ação Política. (Org.) BURSZTYN, M. In: A Difícil Sustentabilidade: Política energética e conflitos ambientais. Rio de Janeiro: Garamond Ltda, p. 107-122. 2012.

LITTLE, P. E. Ecologia política como etnografia: um guia teórico e metodológico. Porto Alegre: Revista Horizontes Antropológicos, n. 25, p. 85-103, jan./jun. 2006.

MARTINS, J. de S. A sociabilidade do homem simples: Cotidiano e história na modernidade anômala. São Paulo: Hucitec, 2000.

PISCIOTTA, K. Pesquisa científica em unidades de conservação da Mata Atlântica paulista. 2003. Dissertação (Mestrado). Programa de Pós-Graduação em Ciência Ambiental da Universidade de São Paulo, São Paulo, 2003.

SANTOS, M. A totalidade do diabo: como as formas geográficas difundem o capital e mudam as estruturas sociais. São Paulo: Contexto Hucitec, p. 31-44, 1977.

TERRA, A. Conflitos socioambientais no parque nacional dos Lençóis Maranhenses. In. PORTO, I. M. R. Geografias em questão. São Luís: Editora UEMA, 2016, p. 177.

- A Pertinência das Novas Abordagens do Território para Análise

Geopolítica dos Assentamentos Rurais In: I Simpósio Internacional de Geografia Política e Territórios Transfronteiriços e II Simpósio Nacional de Geografia Política, Território e Poder, Foz do Iguaçu, 2011.

ZHOURI, A.; OLIVEIRA, P. Desenvolvimento, conflitos sociais e violência no Brasil rural: o caso das usinas hidrelétricas. Revista Ambiente \& Sociedade, v. 10, n. 2, p. 119-135, jul./dez. 2007.

ZIMMERMANN, N. Os desafios da organização interna de um assentamento rural. In: MEDEIROS, L. et al. (Org). Assentamentos rurais: uma visão multidisciplinar. São Paulo: Edunesp, 1994. 